\section{EN TORNO AL MOSAICO CANADIENSE. UNA REFLEXIÓN SOBRE LA GESTIÓN POLÍTICA DE LA INMIGRACIÓN EN CANADÁ}

\author{
Valeriano Esteban \\ Universidad de La Laguna \\ Ana López-Sala \\ Consejo Superior de Investigaciones Científicas
}

\begin{abstract}
The aim of this article is to explore and analyze the main goals and the evolution of immigration policy in Canada since 1850 to nowadays. As a country of immigration the question of migration regulation and the admission of immigrants became a central issue in the national and the academic debate around the identity and the management of pluralism in Canada. Over the years, attitudes toward immigration and the development of immigration policies have evolved, reflecting economic, political, cultural and social issues in this country.
\end{abstract}

KEY WORDS: Canada; Migration Policy; Multiculturalism; reasonable accommodation policy; integration.

\section{INTRODUCCIÓN}

"La diversidad es nuestra fuerza" es el lema de la ciudad de Toronto, una de las ciudades con mayor porcentaje de población de origen inmigrante de Norteamérica. Desde 2001, más de un millón de personas han migrado hacia Canadá y cerca del $40 \%$ del total se han establecido en el área metropolitana de Toronto, donde, según los datos oficiales, casi dos millones y medio de residentes nacieron en el extranjero. Aunque la presencia de minorías visibles y la diversidad étnica de la población y de los ciudadanos canadienses no es tan abultada ni tan intensa en otras zonas del país, la política canadiense de inmigración ha despertado el interés internacional por la bondad de sus resultados en la esfera social y económica, especialmente en un momento en el que destacan los retos y las dificultades que acarrea la gestión de los flujos migratorios.

El extenso territorio canadiense habitado en un principio por los hoy denominados pueblos nativos o "primeras na-
THE CANADIAN MOSAIC: AN ANALYSIS OF HOW CANADA MANAGES IMMIGRATION POLICY

RESUMEN: El propósito de este artículo es explorar y analizar los principales objetivos y la evolución de la política de inmigración en Canadá desde mediados del siglo XIX hasta la actualidad. Como un país de inmigración, la cuestión de la regulación migratoria y de los procesos selectivos en la admisión de inmigrantes se han convertido en elementos centrales del disputado debate académico y político en torno a la identidad y la gestión de la diferencia en Canadá. Sin embargo, como veremos, la política migratoria ha evolucionado a lo largo del tiempo por una combinación de intereses de naturaleza económica, cultural, social y política.

PALABRAS CLAVE: Canadá; política de inmigración; multiculturalismo; acomodo razonable; integración.

ciones" fue, durante siglos, primero conquistado y luego repoblado por sucesivas oleadas de inmigrantes que construyeron una nueva nación formada sobre la base de la pluralidad de orígenes. Esta diversidad en su poblamiento ha conformado la idea de Canadá, y su narración, como un país clásico de inmigración.

Con la aprobación de la Multiculturalism Act en 1988, Canadá se transformó además en el primer país oficialmente defensor del multiculturalismo. Como nación de inmigrantes todos sus miembros debían festejar la diferencia y mostrarse orgullosos de la contribución que las diferentes herencias culturales aportaban a la diversidad nacional. Pero el camino recorrido hasta la proclamación del Multiculturalismo como política oficial ha estado sembrado de obstáculos y la cuestión de la identidad ha articulado una buena parte de las reclamaciones y de las preocupaciones internas en torno a la conformación de la sociedad y de la comunidad política canadiense. 
La noción de Canadá como un país de inmigrantes es, por añadidura, un principio disputado. Algunos autores han sostenido que esta visión resulta excesivamente parcial y simplista. En su opinión, la inmigración no ha sido un componente determinante en la construcción del mito nacional, a pesar de que, por un efecto casi mimético con su poderoso vecino del sur, se le haya definido como tal durante generaciones. Entre los defensores de esta propuesta surge el argumento de que el elemento central de la construcción nacional canadiense descansa en la existencia de dos naciones fundacionales -con una lengua, cultura e historia propia- y en la relación entre ellas. Es éste, por tanto, un elemento que antecede al "componente migratorio" en la mitología nacional (Hawkins, 1988, 1991; Fleras, y Elliot, 1990)'. La historia canadiense se caracterizaría, desde esta perspectiva, por las relaciones existentes entre las minorías indígenas (las denominadas hoy "primeras naciones"), las dos minorias subnacionales firmantes de la "carta constitucional" y las nuevas minorias que se incorporaron posteriormente en sucesivas oleadas migratorias. La inmigración se convierte, por tanto, en una cuestión relevante y crítica para entender los acuerdos políticos entre estos tres sectores de la sociedad canadiense, así como por su efecto sobre el equilibrio demográfico y cultural de la nación².

En segundo lugar, la narración de la nación canadiense ha expresado el exitoso tránsito desde su condición de territorio colonial a la construcción de una nación con una identidad singular en la que ha jugado un papel determinante la consideración de ciertas "razas", de cierto componente humano, como incompatible con la ciudadanía. Este aspecto explica no sólo el tratamiento que recibieron las minorías indias, forzadas durante décadas a vivir en reservas, sino el celo de políticos y burócratas por restringir la llegada, por contener la admisión de aquellos nacionales considerados indeseables.

Las cifras, sin embargo, han convertido en indiscutible, durante décadas, la aportación de la inmigración en el desarrollo social, económico y político de Canadá. Así, para un "país de inmigración", la cuestión de la admisión de extranjeros resulta crucial. Los objetivos, las metas de la política inmigratoria canadiense han reflejado históricamente la confluencia de intereses, muchas veces en conflicto, en el interior de la comunidad, así como la difusión o fragmentación de la responsabilidad entre sectores pú- blicos y privados o entre los niveles federales, provinciales y locales de gobierno.

El propósito de este artículo es realizar un somero análisis de la evolución de la política de inmigración canadiense desde mediados del siglo pasado hasta la actualidad tomando en consideración las ideas y los intereses más influyentes que le dieron forma. Como veremos, esta evolución se ha visto afectada por la transformación a lo largo del tiempo de la idea de comunidad nacional, por una determinada definición de los individuos que debían constituir el demos canadiense.

Sin embargo, como ponen de manifiesto los análisis previos, también debemos hacer mención a otros factores influyentes en su conformación. Hasta la fecha, los estudios sobre la política migratoria canadiense pueden englobarse, a grandes rasgos, dentro de dos grandes escuelas (véase Simmons y Keohane, 1992). La primera línea de interpretación sostiene que las fuerzas productivas y las necesidades del sistema capitalista han moldeado, en exclusiva, las decisiones adoptadas en esta materia. En este marco de análisis, el Estado se presenta como un actor que facilita los intereses de las élites económicas y que fomenta el reclutamiento de mano de obra cuando así lo demanda la economía nacional. Otros autores mencionan la combinación de los factores económicos con los posicionamientos culturalistas o racistas en los procesos de toma de decisiones. Así se explicaría, por ejemplo, el reclutamiento temporal a finales del XIX de coolíes chinos para el sector minero y la construcción del ferrocarril frente a la promoción del establecimiento permanente de colonos europeos en las provincias agrícolas del oeste.

La segunda escuela ha enfatizado el papel del Estado y de las minorías nacionales en el diseño de esta política concediendo un menor peso a la influencia de intereses de naturaleza económica. Este tipo de investigaciones señalan el significativo rol de los actores estatales, en concreto de los burócratas y de los líderes políticos, de uno u otro signo, en el devenir de la política inmigratoria canadiense.

Como veremos a lo largo de este artículo, los factores económicos, políticos y "culturales" pueden ser considerados los elementos más influyentes, con un protagonismo mayor o menor según el período, en la configuración de esta política desde el momento de la confederación cana- 
diense hasta nuestros dias. Los equilibrios entre estos tres componentes han moldeado la composición de los flujos laborales durante décadas. Este análisis, sin pretensión de exhaustividad, tiene también el propósito de dar a conocer al público español las debilidades y fortalezas de este caso, tan poco conocido en nuestro país, a pesar de su relevancia internacional.

\section{LOS ORÍGENES DE LA REGLAMENTACIÓN CANADIENSE EN MATERIA MIGRATORIA}

La segunda mitad del siglo XIX fue testigo en Canadá, al igual que en otros países norteamericanos y europeos, de una creciente preocupación por la cuestión migratoria. El liberalismo económico eliminó los impedimentos mercantilistas y estableció un sistema de libre mercado que incluía la liberalización de los movimientos de población, provocando una transformación de gran calado en las dinámicas migratorias: lo que algunos autores han denominado la revolución de la salida (Zolberg, 2007). La ideología liberal consideraba la libertad de emigración como uno de los principios de la nueva organización social, de ahí que fuera precisamente en este período cuando las constituciones de corte liberal reconocieron la libertad migratoria como uno de los derechos fundamentales del ciudadano.

Aunque franceses y británicos fueron en un primer momento los colectivos más influyentes en el proceso de construcción nacional, tanto por su número como por el peso de sus afiliaciones culturales, la población de lo que hoy es Canadá fue, desde sus orígenes, culturalmente diversa. Individuos de las más variadas nacionalidades se instalaron en este país norteamericano entre los siglos XVII y XIX, empleándose como pescadores, agricultores, profesionales liberales o comerciantes. Esta población incluía, entre otros, a una numerosa comunidad judia, ubicada mayoritariamente en Quebec, alemanes y holandeses, suecos, polacos, negros (esclavos manumitidos y fugitivos procedentes de Estados Unidos) y menonitas originarios de Centroeuropa.

El inicio de la regulación de los flujos de entrada se remonta en el caso canadiense a la segunda mitad del siglo XIX. En los debates que acompañaron la creación de la Confederación de 1865, la promoción de la inmigración se incorporó como un elemento central de la agenda política, debido a su consideración como uno de los beneficios primordiales de la unión de las colonias británicas norteamericanas y una de las piedras angulares del futuro desarrollo nacional. En esta primera etapa de la política canadiense, que transcurre entre 1869 y 1896, el objetivo primordial de la intervención fue el reclutamiento de pobladores y trabajadores como instrumento de mejora social y económica. A pesar de ello, esta declaración de intenciones no se tradujo en una política activa de inmigración como la que observamos en décadas posteriores. El desarrollo demográfico que impulsaron los primeros gobiernos tuvo, sin embargo, un componente selectivo. La primera ley federal de 1869 reconoció ya la autoridad del Estado para controlar la entrada de aquellos individuos considerados poco deseables, como personas sin recursos o con problemas físicos o psíquicos. La política poblacionista que puso de manifiesto el vínculo tradicional entre inmigración y desarrollo agrícola y que pretendía la expansión y colonización hacia el Oeste se rompió durante la década de los ochenta cuando el gobierno laborista declaró como objetivos prioritarios de su agenda el desarrollo de la industria canadiense (Whitaker, 1991) y el reclutamiento de trabajadores para la construcción de infraestructuras, como el Canadian Pacific Railway.

En este período los flujos migratorios que se dirigieron hacia Canadá no fueron estadísticamente cuantiosos, tanto si los comparamos con el volumen de las décadas posteriores, como con el influjo actual. En 1871 sólo el $8 \%$ de la población canadiense no formaba parte de las denominadas minorias indígenas o first nations (indios y esquimales) o de las minorías nacionales (británicos y franceses). Este porcentaje se elevaba hasta el $9 \%$ una década después, situándose en torno al $10 \%$ a principios del $X X^{3}$. Podemos afirmar, sin embargo, que en términos demográficos esta política resultó un fracaso. El saldo migratorio negativo mostraba una cuantiosa emigración hacia Estados Unidos de ciudadanos canadienses e inmigrantes por sus mejores condiciones climáticas y agrícolas. También se produjo una considerable emigración de población de origen francés hacia el sur. El deseo de muchos franceses de aceptar empleos en la industria textil norteamericana, antes que establecerse como agricultores en las praderas del oeste, truncó el sueño de Cartier de un Quebec en el oeste (Hawkins, 1991).

En las últimas décadas del XIX se produjo, sin embargo, un incremento de los flujos procedentes de Asia, una de 
las cuencas más importantes de la inmigración actual. A pesar de las restricciones oficiales, el número de asiáticos ascendía a varios miles en 1881 y sólo en Hong Kong y Cantón fueron reclutados más de 15.000 ciudadanos chinos en los primeros años de la década de los ochenta. El número total de inmigrantes procedentes de este continente, incluyendo japoneses e indios, superaba los 24.000 en 1901 llegando a representar en la Columbia Británica el $11 \%$ de la población. El control interno ejercido sobre esta población se centró en la restricción de sus actividades económicas, en el desarrollo de medidas que contuvieran la instalación, bajo el supuesto de que se trataba de una inmigración temporal, y en la exclusión de la ciudadanía. La posición oficial era que se debía canalizar esta mano de obra hacia la minería y las obras de construcción del ferrocarril y que debía emplearse por cuenta ajena, por lo que se limitó severamente su actividad comercial y la posesión de tierras. Esta regulación confinó a los primeros inmigrantes asiáticos en ciertas actividades y territorios.

La acción del Estado canadiense en materia migratoria durante las décadas finales del siglo XIX puede ser calificada como tímida, excepto, como hemos señalado, en el caso de las iniciativas destinadas a la regulación y el control del establecimiento de población de origen asiático ( $L i, 1979$; Wickberg, 1982). A pesar de que los flujos migratorios tuvieron una gran influencia en el desarrollo y la industrialización nacional, el gobierno federal se mostró reticente a asumir un papel fuerte en el diseño y la implantación de la política migratoria, permitiendo la intervención activa del sector privado y de las fuerzas del mercado. Durante este período los actores dominantes en la construcción de la política fueron los empleadores, los sindicatos y los nacionalistas (o nativistas). Los empresarios demandaron una política abierta y agresiva en el reclutamiento, mientras que los sindicatos exigieron al Estado medidas más restrictivas ante el temor de que la llegada de inmigrantes, principalmente asiáticos, pudiera traducirse en una disminución de los ingresos y de las condiciones laborales de la clase trabajadora autóctona. Los nacionalistas anglocanadienses también apoyaron este tipo de demandas, aunque por otras razones. Su preocupación fue, fundamentalmente, el desarrollo de una sociedad homogénea basada en los valores, las instituciones y las tradiciones anglosajonas. Los nacionalistas canadienses apoyaron, en definitiva, una política restrictiva que promocionase y primara la llegada de inmigrantes británicos. Los francófonos, por su parte, exigieron una intervención que no alterara el equilibrio cultural y lingüistico de Canadá en el tiempo de la Confederación (Kelley y Trebilcock, 1998).

Resulta evidente la influencia tanto de factores de naturaleza económica como de la definición de "razas deseables" en la filosofía que impregnó el desarrollo de la política migratoria canadiense durante la segunda mitad deI XIX. La percepción de la inmigración como un proceso definitivo, que suponía la incorporación a la vida social y política de la nación, impulsó el empleo de instrumentos de selección basados en criterios étnicos que moldeó durante varias décadas la composición de las llegadas.

La era Shifton ${ }^{4}$, la segunda etapa que transcurre entre 1896 y 1905, supuso un punto de inflexión en el papel jugado por el Estado canadiense. Con la ley de 1896 se puso fin a un período en el que la entrada de población no estuvo sometida a controles estatales, iniciándose una época caracterizada por el reclutamiento activo, pero condicionado en cuanto a la procedencia. En los primeros años del siglo se desarrolló una política estatal muy intervencionista y centralizada. La inmigración se transformó en objeto de producción de políticas públicas y de órganos administrativos de gestión. El objetivo de la intervención estatal, alimentada por la propia concepción de Shifton acerca del tipo de población necesaria para Canadá, fue la colonización del Oeste mediante el reclutamiento de granjeros experimentados procedentes de Europa, especialmente de los paises del centro y el este del continente. De ahí que este período no sólo aumentase el volumen migratorio, sino que se produjera una diversificación de las procedencias. Entre 1897 y 1914 se establecieron en Canadá alrededor de dos millones y medio de personas. Aunque la mayor parte de estos inmigrantes procedian de Gran Bretaña e Irlanda también se instalaron un número considerable de alemanes, escandinavos, holandeses, rusos, austríacos, polacos, italianos y judíos. Por ello, esta etapa ha sido descrita como el inicio del boom de la inmigración ultramarina hacia este pais norteamericano.

Las instituciones encargadas de la inmigración se dedicaron a la canalización de los flujos hacia los territorios occidentales, el reparto de tierras y el desarrollo de medidas de acogida. El reclutamiento de trabajadores industriales perdió peso frente al de colonos, siguiendo una filosofía similar a la de otros países, que se condensa adecuadamente en el fa- 
moso eslogan de Alberdi en Argentina, "gobernar es poblar". El reclutamiento de colonos, sin embargo, también desató algunas reticencias entre ciertos sectores de la emergente sociedad canadiense por su talante conservador.

Durante estos años se aprecia un discurso implícito de exclusión ante la llegada de población negra. La política de inmigración puede ser considerada ya en ese momento una política racialmente selectiva, aunque esta posición no tuviera un reflejo en la normativa (Avery, 1995). En este periodo la inmigración se transformó también en fuente de duras controversias donde confluyeron distintos intereses de grupos sociales y políticos. Aunque algunos sectores empresariales presionaron al Estado con el fin de promocionar la llegada de población no blanca para integrar un proletariado industrial necesario en el desarrollo del pais, la opinión pública canadiense fue hostil a la entrada de grupos considerados no asimilables.

De hecho, el debate sobre la inmigración en estos años se centró esencialmente en torno a la importancia de los elementos culturales y raciales como criterios selectivos en las entradas. Esta filosofía de la inmigración tuvo su manifestación más expresiva en la construcción de la política del White Canada, que se extiende de 1905 a 1966.

\section{La politica del White Canada}

El desarrollo de la política del White Canada coincidió con un período crítico en la historia canadiense, el de la consolidación del Estado nacional. La hostilidad hacia los inmigrantes no blancos y la determinación de mantenerlos fuera de las fronteras comenzó durante los primeros años de la fiebre del oro, cuando numerosos trabajadores chinos se asentaron en la Columbia Británica (Baureiss, 1985). Como en el caso de otros países clásicos de inmigración, la idea de comunidad nacional se moduló a través de la construcción de diversas categorías de extranjeros articulando durante décadas las vías de selección para el desarrollo económico y el poblamiento y excluyendo a aquéllos considerados no aptos en términos raciales (Weil, 2001). Desde 1880 la normativa fue introduciendo, cada vez con más intensidad, elementos que limitaban la entrada de población no blanca. El poder del Estado para excluir a los inmigrantes considerados no deseables se afianzó con las
Leyes de Inmigración de 1910 y 1919. Ambas se aprobaron con el deseo de restringir severamente tanto la entrada de ciudadanos chinos, japoneses e indios, como la de negros norteamericanos, africanos y caribeños (Calliste, 1994).

Los motivos que explican el desarrollo de este tipo de política no sólo en Canadá, sino también en Australia fueron, como ha defendido de forma muy persuasiva Freda Hawkins, el claro deseo de construir y preservar sociedades y sistemas políticos similares al del Reino Unido, así como el objetivo de dotar a las poblaciones europeas de un papel clave en el proceso de formación nacional (Hawkins, 1991). En la emergente construcción nacional de ambos paises y en el proceso de creación de las estructuras estatales, la madre patria fue la principal fuente de ideas politicas, de capital y de conocimiento científico y técnico. En un primer momento las medidas de contención de la llegada de poblaciones no deseadas tuvo un carácter disuasorio, pero, desde la entrada en vigor de la Ley de 1910, la política racialmente selectiva se convirtió en explícita a través de la prohibición de los inmigrantes de cualquier raza juzgada como inconveniente o incompatible con los requisitos de este ideal (Ongley y Pearson, 1995).

Estas creencias raciales, tan de moda en aquel momento, junto con el temor de que la Revolución Rusa de 1917 pudiera ser exportada, condujeron también a una política muy restrictiva de importación de mano de obra originaria de otras regiones europeas (Fleras y Elliot, 1990). Por eso desde los años treinta se pretendió frenar también los flujos de los paises del sur y el este de Europa. Así, en 1931 se designaron tres tipos de inmigrantes preferentes: súbditos británicos con medios económicos suficientes, irlandeses y ciudadanos estadounidenses dependientes de residentes permanentes en Canadá. En conclusión, el sustento principal de la política del White Canada fue el deseo expresado de mantener una identidad nacional y una comunidad política homogénea en términos culturales y raciales de acuerdo con el principio de angloconformidad (Palmer, 1994).

No debemos olvidar, sin embargo, que los factores económicos también jugaron un papel sobresaliente durante el período de entreguerras en el impulso de las restricciones migratorias. El temor al desempleo y a la competencia por los puestos de trabajo en un momento de recesión económica moldeó una política de inmigración con muchos límites a la llegada.

ARBOR CLXXXVI 744 julio-agosto [2010] 657-669 ISSN: 0210-1963 
Sin embargo, el crecimiento demográfico de Canadá entre 1896 y 1930 tuvo efectos fundamentales en el futuro del pais. Mientras que las provincias del este mantuvieron su dualismo cultural franco-británico, las provincias del norte y del oeste adquirieron una composición muy diversa que suscitó rechazo. Los anglocanadienses mostraron, por ejemplo, enorme preocupación ante el bajo nivel de "canadización" de algunas minorias. El fervor patriótico que acompañó a la Primera Guerra Mundial y la limitación de los recursos durante el período de entreguerras promovió la abolición de las escuelas bilingües y la redefinición de una ciudadanía canadiense, en exclusiva, para los inmigrantes de origen europeo. Los ataques racistas y las oleadas antiinmigración tampoco fueron infrecuentes en los años treinta. La lealtad a la nación de las nuevas comunidades fue objeto de controversia entre los integrantes de las "naciones fundacionales".

Tras la Segunda Guerra Mundial se inició una etapa de espectacular desarrollo económico y social en este país norteamericano. El mantenimiento durante décadas de esta política racialmente selectiva y su lógica discriminatoria no impidió la promoción de las llegadas en momentos de expansión. Así, la década de los cuarenta fue testigo de la implantación de una política activa de reclutamiento de trabajadores extranjeros para hacer frente a las necesidades económicas. La inmigración fue uno de los factores que permitieron la duplicación de la población canadiense entre 1945 y 1965, ya que el reclutamiento se acompañó de la promoción de la instalación definitiva y la reagrupación. Los distintos retos que surgieron de la instalación exigieron el desarrollo de una política comprehensiva de inmigración que hizo especial hincapié, por primera vez, en la integración social y económica de los extranjeros. El resultado natural de esta política fue el desarrollo de las instituciones de la inmigración, así como un elemento que ha permanecido hasta nuestros días: la fragmentación administrativa de la gestión.

La regulación de la migración laboral, cualificada y no cualificada, fue un objetivo establecido a través de las instituciones federales. En este proceso fue fundamental lo que se conoce como inmigración subvencionada ${ }^{5}$. El primer ministro MacKenzie King desarrolló durante las décadas centrales del siglo XX una administración sustentada en varios principios: a) el reclutamiento activo de mano de obra para consolidar el desarrollo demográfico y econó- mico de la nación, b) la selección de los inmigrantes de acuerdo con la capacidad de absorción del país, c) el mantenimiento de las limitaciones a la llegada de población no blanca bajo el supuesto de que debía mantenerse el "carácter original" de la ciudadanía canadiense -la inmigración no debía distorsionar la "vocación europea" de la nación- y d) la adecuación de la política de inmigración a los objetivos de la política interior.

En este período se aprecia, sin embargo, cierta relajación del White Canada, aunque la Ley de Inmigración de 1952 sigue considerando la raza como uno de los criterios condicionantes de la elegibilidad de los migrantes. Durante los años cincuenta la mayoría de las entradas corresponden a británicos y europeos del centro y norte, fundamentalmente alemanes y holandeses, pero la inmigración del sur y del este empezó de nuevo a cobrar un peso importante.

Como ha señalado Palmer, la prosperidad económica, las transformaciones sociales y las nuevas asunciones intelectuales disminuyeron el nativismo y el prejuicio y abonaron el terreno para la aceptación del pluralismo en los sesenta y los setenta (Palmer, 1975). La deslegitimación de las teorias sobre la superioridad racial y los sentimientos antisemitas también tuvieron un papel destacado en esta transformación. No debe olvidarse la vergüenza histórica que supuso para Canadá los desafortunados acontecimientos del St Louis ${ }^{6}$ (Abella y Troper, 1998). La década de los cincuenta supuso, en definitiva, un tiempo de cambio en las actitudes de los canadienses ante la diversidad étnica. En este período el Estado empezó a intervenir activamente en la política social adquiriendo cierto protagonismo en la "creación" de actitudes positivas hacia el pluralismo, algo que se reflejó en las nuevas leyes canadienses de nacionalidad donde se realizó una interpretación de la ciudadanía cada vez más alejada de la clásica francobritanidad (Laponce y Safran, 1996).

\section{NUEVOS CRITERIOS DE LA REGULACIÓN MIGRATORIA: EL DESMANTELAMIENTO DE LA POLITICA RACIALMENTE SELECTIVA Y LA IMPLANTACIÓN DEL SISTEMA DE PUNTOS}

A mediados de los sesenta se eliminó el sistema discriminatorio de cuotas basado en orígenes nacionales y étnicos y fue aprobado un nuevo régimen migratorio en el que el 
criterio más importante para la admisión fue el parentesco con ciudadanos o residentes y la cualificación profesional. A partir de 1966 Canadá abrió las puertas a la inmigración no europea. Durante los setenta, sus principales fuentes migratorias fueron Jamaica, India, Filipinas, Portugal, Grecia, Italia y Trinidad. Esta modificación legal impulsó la intensa diversificación étnica, religiosa y lingüística que ha experimentado la población y la ciudadanía canadiense desde los setenta.

Este cambio de orientación de la política ha sido ampliamente analizado por los especialistas. Algunos autores han subrayado que fueron los criterios de naturaleza moral los que terminaron por inducir la eliminación del anterior modelo. La imagen y el papel de Canadá en la comunidad internacional exigían el desarrollo de medidas más acordes con el pluralismo. Como han destacado Fleras y Elliot, este tipo de política discriminatoria era moralmente indefendible por más tiempo (Fleras y Elliot, 1992).

El desarrollo económico de Europa redujo además los estímulos a la migración, limitando enormemente las fuentes de los flujos de mayor tradición. Por eso Passaris describió la política canadiense en relación con este cambio como un triunfo de la economía sobre la discriminación, ya que las demandas del mercado laboral sólo podian ser cubiertas con trabajadores de nuevos países (Passaris, 1984). La nueva política impregnada por principios más humanistas y universalistas sostuvo que la inmigración era una fuente de recursos humanos y de enriquecimiento cultural que podía, asimismo, afectar a la estructura de clases ${ }^{7}$ (Elliot y Fleras, 1990).

Lo más destacado del cambio en la esfera de la regulación migratoria canadiense en este momento fue la profunda transformación de los criterios selectivos. Observamos así un tránsito hacia nuevas variables para la admisión en donde los vínculos familiares, las razones humanitarias y los credenciales han determinado las posibilidades de establecimiento en este país norteamericano (López Sala, 2005b). Esta filosofía de la regulación se concretó en la aprobación en 1967 del denominado sistema de puntos, una política que se mantiene hasta el momento actual (Li, 2008; Reitz, 2007). El sistema de puntos, inspirado en la legislación australiana, se convierte en un mecanismo combinado de selección en donde se conjugan diversas variables como las cualificaciones, la formación y la ex- periencia profesional, la edad, la capacidad de inversión o los conocimientos lingüísticos.

La Ley de Inmigración de 1976 y las siguientes regulaciones de orden menor mantuvieron el esquema de clasificación de 1967, pero introdujeron algunas pequeñas modificaciones. Por ejemplo, el número de inmigrantes recibidos como familiares creció en términos relativos durante los setenta y ochenta y los inmigrantes independientes incluyeron nuevas categorias de inversores y empresarios.

Este sistema de puntos se ha compaginado con una política planificada y proactiva que ha promovido la inmigración permanente $y$ en donde las provincias han adquirido cada vez mayores de competencias. Este modelo ha sido apoyado por la clase política y la opinión pública al margen de las fluctuaciones económicas y no ha representado una fuente importante de controversias en el debate electoral nacional.

En los noventa, el sistema de puntos ha reajustado los mecanismos de selección promocionado el reclutamiento de trabajadores de alta cualificación a partir del progresivo énfasis canadiense en una economía basada en el "conocimiento" (véase Boyd, 2008). La inmigración se percibe como una herramienta para promover el consumo, la creación de inversiones y mejorar los niveles de productividad y de innovación tecnológica del país. Esta lógica ha transformado a los "inmigrantes independientes" en el 60\% de los 200.000-250.000 trabajadores permanentes admitidos cada año, frente al $28 \%$ que acceden dentro de lo que se conoce como "clase familiar" y el $12 \%$ bajo el estatuto de refugiado.

Este tipo de política ha incrementado de forma aún más aguda la diversidad de la composición de los flujos migratorios. Así, por ejemplo, en las dos últimas décadas, el principal continente de origen ha sido Asia, con el predominio de los trabajadores procedentes de China, India, Filipinas y Pakistán. El último censo de 2006 subrayaba, asimismo, el crecimiento experimentado por las denominadas minorías visibles, que representan algo más del 16\% del total de la población canadiense (Drieger, 1996; Statistics Canada: 2008).

En definitiva, desde finales de los años sesenta, Canadá elaboró una política activa de inmigración bajo el supuesto de que los migrantes suponían un recurso estratégico para

ARBOR CLXXXVI 744 julio-agosto [2010] 657-669 ISSN: 0210-1963

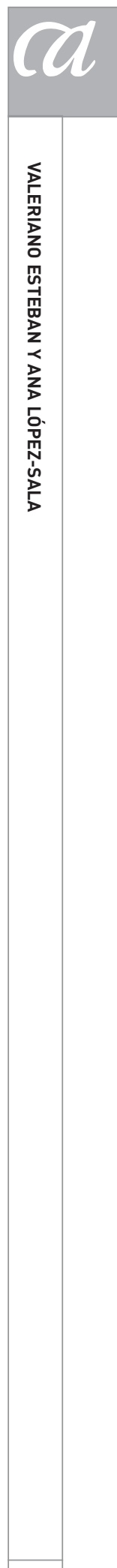

663 
la economía. Esta política incluyó, de forma prioritaria, mecanismos de selección basados en los credenciales. Esta gestión de la inmigración, ambiciosa en sus dimensiones, ha promovido, asimismo, el establecimiento y la adquisición privilegiada de la nacionalidad (Reitz, 2007; Kelley y Trebilcock, 1998; Papademetriou, 2007; Knowles, 2007) y la transferencia de algunas competencias (selección, integración, reagrupación familiar) a las provincias (Li, 2008; Siemiatycki, 2008).

\section{El mUlticulturalismo CANADIENSE}

El modelo canadiense de gestión de la diversidad cultural también experimentó un profundo cambio en los setenta. Este modelo ha despertado la atención, y la admiración, a pesar de sus detractores, entre académicos y hacedores de políticas por su carácter inclusivo así como por la amalgama de formas de reconocimiento que incorpora en la esfera pública. El modelo canadiense, con ramificaciones en la gestión interna de la diversidad cultural, religiosa y lingüistica de las minorías inmigrantes y subnacionales, ha tenido su mejor símbolo en el denominado multiculturalismo. Esta propuesta normativa y política, que se inaugura en 1971 tras el desmantelamiento de las medidas racialmente selectivas, propuso una profunda reformulación de la identidad nacional, en donde el pluralismo cultural se enunciaba como principio articulador.

Las transformaciones en la esfera de la integración de los inmigrantes no fueron fruto de la casualidad. Coinciden con un período de profunda reflexión, de búsqueda, de reformulación de la identidad canadiense, un proceso catalizado, en parte, por el aumento de las demandas de reconocimiento que realizaron otro tipo de minorias: los pueblos indígenas y los nacionalistas francófonos.

Por ello, el multiculturalismo en el caso canadiense no puede ser interpretado, en exclusiva, como un producto resultante de la diversidad que incorpora la inmigración, sino como un contrato social y político que alimenta y reformula el debate, con la metáfora del mosaico como referencia, en torno a la unidad y la identidad de la nación y de la sociedad canadiense (Trudeau, Stanfield y Lewis, 1975; Helly, 1996; Fleras y Elliot, 1992; Troper, 2003; Roberts y Clifton, 1990).
En esta política estatal que adquirió rango de ley en 1988, las diferencias culturales son percibidas como un componente intrínseco del orden social, político y moral (Colom, 2001). La diversidad es incorporada, asimismo, en el contorno de la ciudadanía. Desde esta perspectiva dicho modelo establece un nuevo tipo de relaciones entre el Estado y las minorías (sean éstas indígenas, inmigrantes o subnacionales) y se articula a través de tres principios: cohesión social, identidad cultural e igualdad de oportunidades y de acceso a las instituciones de la sociedad de acogida. La alternativa multicultural, por tanto, sugiere, frente a otros modelos de gestión, que es posible reconocer que las minorias tienen derecho a utilizar su propia lengua, a practicar su religión, a mantener sus costumbres, en definitiva, a mantener su cultura distintiva sin que se ponga en peligro la unidad política y social de la sociedad nacional.

A la igualdad formal en la esfera pública se añade la promoción desde el Estado de un trato diferencial también en el ámbito de lo público (Arango, 2003). Por tanto, la plasmación política de estos principios exige una modificación de las instituciones de la sociedad mayoritaria para hacerlas más permeables a la participación, en condiciones de igualdad, de las minorías inmigrantes, así como el desarrollo de políticas sociales que incluyan medidas especiales. Otro de los fines de las políticas multiculturales ha sido la promoción del mantenimiento de la especificidad cultural de estas minorias (lo que puede denominarse reproducción cultural), a través de la intervención en ámbitos estratégicos como la política educativa y lingüística.

El rechazo de la noción de una cultura única y dominante como elemento integrador de la comunidad política debía insistir en el reconocimiento de las contribuciones realizadas por todas las culturas a la nación canadiense. Las medidas implantadas pretendían conseguir la incorporación de "todos" a las instituciones sociales y económicas del país y asegurar la armonía social a través de la eliminación de todo tipo de discriminación.

No debemos olvidar que la implantación y el desarrollo de las políticas multiculturales se ha acompañado de agitados debates públicos y de profundas controversias, a pesar de que la mayor parte de la opinión pública han mostrado reiteradamente su alianza con los principios que defienden. Una de las críticas más frecuentes que han recibido es que este tipo de políticas han minado la tendencia histórica 
de los inmigrantes a integrarse en la sociedad de acogida fomentando peligrosamente la división social a lo largo de líneas étnicas y culturales. Éste fue, por ejemplo, el principal argumento de Neil Bissoondath en su libro Selling Illusions: The cult of Multiculturalism in Canada, que se convirtió a mediados de los noventa en un best-seller. Sin embargo, desde la implantación de esta política en Canadá han aumentado considerablemente los conocimientos lingüisticos entre los inmigrantes de primera y segunda generación y han crecido apreciablemente la proporción de matrimonios mixtos y la tolerancia hacia las minorias. Aunque es indudable que ha mejorado el estatuto simbólico y cultural de las minorías inmigrantes, es cierto también que algunos colectivos siguen sufriendo tasas de desempleo y de fracaso escolar mucho más altas que la población autóctona y que se han visto muy castigados por ciertos problemas sociales como el alcoholismo, la drogadicción o la violencia familiar.

Desde los noventa las críticas se han centrado en determinar si los enormes gastos estatales que ocasiona la reproducción de las culturas originarias de los inmigrantes pueden justificar los efectos positivos de este tipo de políticas. La crisis económica ha tenido un efecto directo en el recorte de los presupuestos para educación y servicios sociales, lo que indudablemente ha afectado a los programas de vivienda y a los de lengua materna.

No debemos dejar de señalar que este modelo de integración, por el que Canadá es bien conocido y admirado internacionalmente, no fue formalmente aceptado como fórmula de gestión en Quebec. Quebec siempre ha defendido que el modelo multicultural canadiense no se ajusta a sus circunstancias. Los quebequeses prefieren el término interculturalismo porque da a entender que son innumerables culturas las que se relacionan o yuxtaponen sin concepto alguno de jerarquía o preeminencia. El interculturalismo busca reconciliar la diversidad etnocultural con la continuidad del macizo o centro francófono y la preservación de los vínculos sociales. Por tanto, el interculturalismo como modelo de acomodo de la diversidad se entiende en el caso de esta provincia canadiense como una propuesta que incorpora el respeto por otras culturas, pero en el contexto del francés como lengua común, y oficial, a través de la conocida Ley 101, y como punto focal de la integración (Seidle, 2009; Esteban Sánchez y López Sala, A., 2009).

\section{DinÁMICAS RECIENTES EN LA POLITICA MIGRATORIA CANADIENSE}

A lo largo de la última década la política canadiense ha experimentado algunos cambios de enorme interés que, sin embargo, no nos permiten hablar de un cambio en el modelo migratorio, aunque sí de algunas nuevas tendencias, cuyo funcionamiento y efectos deberán ser evaluados en los próximos años.

En la esfera del control migratorio, apreciamos en primer lugar un incremento de las iniciativas de vigilancia fronteriza y su perfeccionamiento, especialmente después de 2001. Esta vigilancia ha incorporado tanto la creación de una agencia de fronteras a finales de 2003 como la firma de acuerdos bilaterales, el más importante con Estados Unidos, y la aplicación de sanciones a compañias de transportes. Se trata, en todos los casos, de medidas similares a las aprobadas y aplicadas en Europa en la última década.

En la esfera del asilo y el refugio, ha aparecido recientemente un deseo explícito de limitar las concesiones, y la firma del Safe Third Country Agreement con Estados Unidos, dentro del programa bilateral de gestión de la frontera común, que entró en vigor a finales de 2004, ha impedido la admisión a trámite de las solicitudes que se realizan en la frontera sur. Esta esfera de la política de inmigración ha incorporado, por tanto, a nuevos actores, observándose un creciente proceso de externalización de la intervención.

A pesar del mantenimiento de la filosofía de la promoción de la inmigración permanente, en los últimos años han crecido de forma significativa los programas de admisión temporal, o al menos han aumentado en sus dimensiones (Goldring, Berhnard, y Landolt, 2008). Las fórmulas de la circularidad migratoria se han aplicado en el caso canadiense particularmente a ciertos perfiles, como los trabajadores agrícolas (Agunias y Newland, 2007; Newland, Aguinias y Terrazas, 2008). De ahí las nuevas comunidades de mexicanos y guatemaltecos que se han incorporado a la economía agrícola en provincias como Ontario. Los programas que más han condensado este nuevo tipo de política han sido el Seasonal Agricultural Workers Program (SAWP), a través del cual se reclutan en torno a 20.000 trabajadores anuales, de los que algo más de la mitad procede de México; y el programa firmado entre FERME, la más importante asociación de empresarios agrícolas de

ARBOR CLXXXVI 744 julio-agosto [2010] 657-669 ISSN: 0210-1963

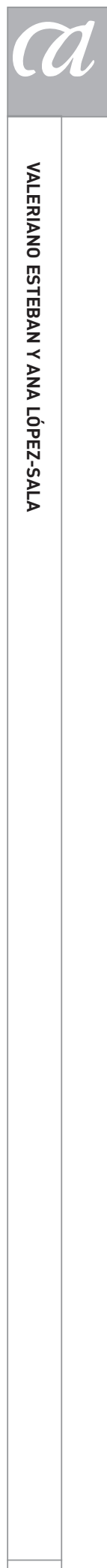

665 
Quebec, y el gobierno de Guatemala, en donde participan también las autoridades de la provincia y la IOM.

A pesar de las ventajas que estos programas representan para los trabajadores agrícolas, destacados por algunos autores (véase Verduzco y Lozano, 2003), el carácter no permanente de estos tipos de flujos, así como la limitación de sus derechos, que se deriva de la temporalidad que acarrea este tipo de migración, ha despertado la atención, y las reclamaciones, de las asociaciones defensoras de los derechos de los migrantes y de algunos académicos (Basok, 2003, 2004 y 2007; Landolt, 2005). Resulta especialmente destacable la debilidad de los mecanismos jurídicos que regulan la transición del estatuto legal de este tipo de trabajadores temporales en permanentes, a diferencia de los mecanismos jurídicos que ha desarrollado la legislación canadiense en el caso de estudiantes y trabajadores cualificados extranjeros. Los resultados de este tipo de políticas en el futuro serán una progresiva segmentación interna de los migrantes y sus procesos asociados de exclusión y estratificación cívica. Para los especialistas, la ampliación de este tipo de programas ha sido el resultado del deseo del gobierno de Harper de enfatizar la inmigración circular, así como la deriva de sus medidas en una política migratoria "moldeada por el mercado" y las necesidades del mercado de trabajo; lo que se conoce en la literatura internacional como private selection and employment-driven selection system.

En los últimos años también ha aumentado la participación de las provincias en la conformación y aplicación de la política migratoria, aunque este proceso tiene una gran tradición. Los primeros acuerdos importantes fueron firmados con Quebec en 1971, aunque el más sobresaliente data de principios de los años noventa. Este último significó la transferencia de competencias en materia de selección y acogida y el reparto de recursos para gestión. En la actual existen acuerdos con ocho provincias. Mientras que las concesiones de nacionalidad y de refugio permanente en manos del gobierno regional, la integración, selección y admisión por reagrupación familiar son áreas del diseño y la ejecución de la política cuya competencia corresponde a las provincias.

A pesar del apoyo que la política del multiculturalismo sigue despertando en los ciudadanos canadienses, en 2006 tuvo lugar un episodio en la provincia de Quebec que ha evidenciado también en el caso canadiense las dificultades de gestión de la diversidad religiosa (Esteban, 2007). Se trató de la llamada "crisis de los acomodos razonables" que provocó la creación por parte del primer ministro de Quebec de la conocida como "Comisión Bouchard-Taylor" (véase Esteban y López Sala, 2009; Seidle, 2009). Aunque sus orígenes son más remotos, la crisis comenzó en 2006 cuando los medios de comunicación empezaron a interesarse en una serie de demandas realizadas por las minorias culturales para "acomodar" su práctica religiosa dentro de las posibilidades que permitía la figura del acomodo razonable en la legislación canadiense ${ }^{8}$. El debate fue recogido y estimulado por algunos partidos políticos y encontró un amplio eco en la sociedad.

Los trabajos de la Comisión duraron varios meses. Una de sus más notables iniciativas fue la de examinar con detalle los episodios que circulaban públicamente en la prensa y en la sociedad y que habian dado lugar a la controversia sobre las demandas "excesivas" de las minorías religiosas (véase Esteban y López Sala, 2009). Con la ayuda de un equipo de colaboradores, la Comisión se tomó el trabajo de reconstruir, de manera prácticamente forense, los hechos de cada uno de estos episodios hasta donde fuera posible. La conclusión principal a la que llegó la Comisión es que en la mayoría de los casos que suscitaron controversia y que despertaron ríos de tinta en la prensa, habia una gran distorsión entre los hechos y las percepciones (veáse Bouchard y Taylor, 2008), algo a lo que el informe se refiere como una "crisis de percepción". El método de trabajo de la propia Comisión fue un ejercicio de amplia democracia participativa en donde se escucharon y recogieron las opiniones de todas las fuerzas sociales y políticas de la provincia. La Comisión destapó los profundos temores de la sociedad de Quebec ante la presencia de las minorias religiosas y la percepción de su capacidad potencial para socavar algunos de los logros de la Revolución Tranquila, en especial, la idea de una sociedad laica y secular, igualitaria y francófona (Esteban y López Sala, 2009).

Quebec siempre ha defendido que el modelo multicultural canadiense no se ajusta a sus circunstancias, pero no han elaborado formalmente un documento político donde se presente la posición propia de la provincia en materia de gestión de la diversidad. Los quebequeses perciben que el modelo canadiense no conduce a una integración. Aunque en la práctica el interculturalismo y el multiculturalismo se parecen mucho, los quebequeses prefieren el término interculturalismo porque no da a entender que son innumerables culturas las que se relacionan o yuxtaponen sin 
concepto alguno de jerarquía o preeminencia. El interés por la cohesión social y la integración es un elemento clave del interculturalismo quebequés que echan de menos en el multiculturalismo canadiense. El interculturalismo busca reconciliar la diversidad etnocultural con la continuidad del centro francófono y la preservación de los vínculos sociales. Una de las conclusiones de la Comisión fue que el interculturalismo debía ser definido oficialmente, por primera vez, como modelo de gobierno de Quebec a través de la elaboración de un documento.

Aunque los trabajos de la Comisión sofocaron la inquietud social, la crisis mostró que la presencia de minorias inmigrantes y religiosas se muestra especialmente cargada de dificultades en el caso de Quebec. Esta situación es, sin embargo, singular en el panorama general canadiense.

\section{NOTAS}

1 El censo de 1870 revela la composición del Canadá inmediatamente posterior a la Confederación. En 1871 residian en este pais 1.082.940 franceses $y$ un total de 2.110.502 británicos -una cifra que incluía a ingleses, galeses, escoceses e irlandeses-. Los otros grupos eran, en términos comparativos, considerablemente menos numerosos. El único colectivo digno de mención era el de los alemanes cuya cifra ascendía a 202.991. El registro incluia también a 29.662 holandeses, 21.496 negros (denominados en aquel momento, africanos) y pequeños grupos de suizos, italianos, españoles y portugueses. Los ucranianos, una de las comunidades más numerosas posteriormente, no aparecen registrados en el censo, al igual que el colectivo chino, concentrado, unos cuantos miles, en la Columbia Británica.

2 En la etapa posterior a la Confederación las iniciativas de promoción de la inmigración como estrategia de construcción nacional fueron recibidas con cierta ambivalencia. El Canadá francés se mostraba reticente ante el reclutamiento de población no francófona por el peligro que ello podia suponer para la supervivencia del francés. La inmigración fue también objeto de controversia por la oposición que manifestaban ciertas comunidades religiosas, así como las organizaciones de trabajadores (véase Fleras y Elliot, 1990).

3 Veáse Royal Commission on Bilingualism and Biculturalism (1970): The contribution of the other ethnic groups, Otawa, Queen's Printer, Libro IV.

4 Ministro del Interior entre 1896 y 1905 durante el gobierno de Laurier.

5 La inmigración subvencionada supuso "la promoción de los movimientos de entrada de familiares o cuasifamiliares de inmigrantes establecidos en Canadá. Las razones por las que el Estado apoyó este tipo de inmigración fueron las bondades que se le atribuyeron a este sistema: a) resultaba un mecanismo adecuado para favorecer a los grupos nacionales ya consolidados y particularmente a aquéllos con fuertes lazos con el pais de acogida, b) eliminaba otros tipos de flujos migratorios considerados menos 'adecuados', y c) limitaba los gastos del Estado en las primeras etapas del establecimiento" (Ongley y Pearson, 1995).

6 En la primavera de 1939 el St. Louis, un barco de lujo cargado con cientos de judíos alemanes, zarpó de la ciudad de Hamburgo e inició un periplo por diferentes paises de América. Las autoridades de Argentina, Uruguay, Paraguay, Panamá, Estados Unidos y Canadá, rechazaron las solicitudes de los desesperados pasajeros. El barco regresó, en junio de 1939, a Europa donde los gobiernos
Aceptado: 13 de septiembre de 2009 
de Holanda, Bélgica y Gran Bretaña ofrecieron protección temporal a sus ocupantes.

7 Veáse Porter, J. (1965): The Vertical Mosaic: An Analysis of Social Class and Power in Canada, University of Toronto Press, Toronto.

8 Se trata de una figura de la legislación laboral que permite ciertos cambios en las condiciones de trabajo para acomodar las especiales circunstancias personales de los empleados. La figura del acomodo también ha incorporado de forma progresiva las especiales necesidades derivadas de las creencias y las prácticas religiosas.

\section{BIBLIOGRAFÍA}

Abella, I. y Troper, H. (1998): "The line must be drawn somewhere: Canada and Jewish Refugees: 1933-1939", en lacoveta, F.; Draper, P. y Ventresca, R. (ed.), A Nation of Immigrants: Women, workers and communities in Canadian History, 1840s-1960s, University of Toronto Press, Toronto.

Agunias, D. y Newland, K. (2007): Circular Migration and Development: Trends, Policy Routes, and Ways Forward, MPI, Policy Brief, Washington.

Arango, J. (2003): "Europa, ¿una sociedad multicultural en el siglo XXI? El caso de España", en Papeles de Economía, n. ${ }^{\circ}$ 98, pp. 2-15.

Atchinson, J. y Westin, C. (1999): "Comparative aspects of Swedish and Australian multiculturalism", en Westin, C. y Koivukangas, 0. (eds.), Scandinavian and European Migration to Australia and New Zealand, CEIFO, Universidad de Estocolmo, Estocolmo.

Avery, D. (1995): Reluctant Host: Canada's Response to immigration Workers, 1896-1994, M and S Publishers, Toronto.
Basok, T. (2003): "Mexican Seasonal Migration to Canada and Development: a community-base comparison", en International Migration, vol. 41, n. 2.

- (2004): "Post-National Citizenship, Social Exclusion, and Migrants' Rights: Mexican Seasonal Workers in Canada" en Citizenship Studies, vol. 8, n. 1 , pp. 47-64.

- (2007): "Canada's Temporary Migration Program: a model despite flaws", Migration Information Source, noviembre.

Baureiness, G. (1985): "Discrimination and Response: The Chinese in Canada", en Bienvenue, R. y Goldstein, J. (ed.), Ethnicity and Ethnic Relations in Canada, Butterworhs, Toronto.

Bissoondath, N. (2002): Selling Illusions. The cult of Multiculturalism in Canada. Penguin, Londres.

Bouchard, G. y Taylor, C. (2008): Fonder I'avenir: Le temps de la conciliation, Commission de consultation sur les pratiques d'accommodement reliées aux différences culturelles, Montreal.

Boyd, M. (2008): "La gestión de los flujos migratorios y los contingentes", en Forum Gestión de la Inmigración y la Diversidad en Canadá y Quebec, Fundación CIDOB, Barcelona, octubre.

Calliste, A. (1994): "Race, Gender and Canadian Immigration Policy: Blacks from the Caribbean, 1900-1932", en Journal of Canadian Studies, vol. 28, n. ${ }^{4}$, pp. 131-148.

Canadian Heritage (1999): Annual Report on the Operation of the Multiculturalism Act, Ottawa.

Colom, F. (2001): El espejo, el mosaico, el crisol. Modelos políticos para el Multiculturalismo, Anthropos, Barcelona.

Dirks, G. (1995): Controversy and Complexity: Canadian Immigration Policy during the 1980s, McGill-Queen's University Press.
Driedger, L. (1996): Multiethnic Canada: identities and equalities, Oxford University Press, Toronto.

Esteban, V. (2007): "La secularización en entredicho: la revisión de un debate clásico de la sociología", en Bericat, E. (coord.), El fenómeno religioso. Presencia de la religión y la religiosidad en las sociedades avanzadas, Centro de Estudios Andaluces, Sevilla.

Esteban, V. y López Sala, A. (2009): "La crisis de los acomodos razonables en Quebec: La comisión Bouchard-Taylor", en Revista Internacional de Filosofía Política, n. ${ }^{\circ} 33$, pp. 191-209.

Fleras, A. y Elliot, J. (1990): "Immigration and the Canadian Ethnic Mosaic", en Li, P. S. (ed.), Race and Ethnic Relations in Canada, Oxford University Press, Toronto.

- (1992): Multiculturalism in Canada: The Challenge of Diversity, Nelson Canada, Scarborough.

Goldring, L.; Berhnard, J. y Landolt, P. (2008): "Transnationalizing Families: Canadian Immigration Policy and the Spatial Fragmentation of Caregiving among Latin American Newcomers", en International Migration, vol. 46, n. ${ }^{\circ} 3$.

Hawkins, F. (1989): Canadian and Immigration. Public Policy and Public Concern, McGill-Queen's University Press, Montreal.

- (1991): Critical Years in Immigration: Australia and Canada compared, McGill-Queen's University Press, Montreal.

Helly, D. (1996): "El Multiculturalismo canadiense: 1971-1995", Ponencia presentada al IV Congreso Internacional de la Asociación española de estudios canadienses, Identidad y Diferencia: la creación de las identidades y la gestión de las diferencias, Sitges, noviembre.

Kelley, N. y Trebilcock, M. (1998): The Making of the Mosaic: a History of Cana- 
dian Immigration Policy, University of Toronto Press, Toronto.

Knowles, V. (2007): Strangers at our Gates. Canadian Immigration and Immigration Policy, 1540-2006, Dundurn, Toronto.

Landolt, P. (2008): "The Transnational Geographies of Immigrant Politics: Insights from a Comparative Study of Migrant Grassroots Organizing", en The Sociological Quarterly, vol. 49, n. 1 , pp. 57-77.

Laponce, J. y Safran, W. (1996): Ethnicity and Citizenship: The Canadian Case, Frank Cass, Londres.

Li, P. (1979): "A Historical Approach to Ethnic Stratification: The case of the chinese in Canada: 1858-1930", en Canadian Review of Sociology and Anthropology, vol. 16, n. ${ }^{\circ}$, pp. $320-$ 332.

- (2008): "Federal and Provincial Immigration Arrangements in Canada: Policy Changes and Implications", en Forum Gestión de la Inmigración y la Diversidad en Canadá y Quebec, Fundación CIDOB, Barcelona, octubre.

López Sala, A. (2005a): Inmigrantes y Estados: la respuesta política ante la cuestión migratoria, Anthropos, Barcelona.

- (2005b): "El control de la inmigración: política fronteriza, selección del acceso e inmigración irregular", en Arbor, n. ${ }^{\circ}$ 713, pp. 27-39.

Newland, K.; Agunias, D. y Terrazas, A. (2008): Learning by doing. Experiences of Circular Migration, Migration Policy Institute, Washington.

Ongley, P. y Pearson, D. (1995): "Post 1945 International Migration: New Zealand, Australia and Canada Compared" en International Migration Review, vol. 29, n. ${ }^{\circ}$ 3, pp. 765-793.

Palmer, H. (1975): Immigration and the Rise of Multiculturalism, Copp Clark Publising, Toronto.
- (1994): "Reluctant Hosts: Anglo-Canadian Views of Multiculturalism in The Twentieth Century", en Tulchinsky, G. (ed.), Immigration in Canada, Copp Clarks, Longman Publishers, Toronto.

Papademetriou, D. (2007): Selecting Economic Stream Immigrants through Points Systems, Migration Policy Institute, Washington.

Porter, J. (1965): The Vertical Mosaic: An Analysis of Social Class and Power in Canada, Universidad de Toronto Press, Toronto.

Reitz, J. (2004): "Canada: Immigration and Nation Building in the Transition to a Knowledge Economy", en Cornelius, W.; Martin, P.; Hollifield, J. y Tsuda, T. (eds.), Controlling Immigration. A Global Perspective, Standford University Press, Stanford, pp. 97-131.

- (2007): "¿Puede ofrecer lecciones a Europa la experiencia canadiense?", en La Vanguardia Dossier. Inmigrantes: el continente móvil, pp. 38-46.

Roberts, L. y Clifton, R. (1990): "Multiculturalism in Canada" en Li, P. (ed.), Race and Ethnic Relations in Canada, Oxford University Press, Toronto.

Royal Commission on Bilingualism and $\mathrm{Bi}-$ culturalism (1970): The Contribution of the other Ethnic Groups, Queen's Printer, Ottawa.

Seidle, F. (2009): "Testing the Limits of Minority Accommodation in Quebec", en Fossum, J. E.; Magnette, P. y Poirier, J. (eds.), The Ties that Bind. Accommodating Diversity in Canada and the European Union, Peter Lang, Bruselas (en prensa).

Siemiatyck, M. (2008): "Citizenship, Settlement and Sociocultural Integration in Canada", en Forum Gestión de la Inmigración y la Diversidad en Canadá y Quebec, Fundación CIDOB, Barcelona, octubre.

Sifton, C. (1975): "Only Farmers need apply" en Palmer, H. (ed.), Immigration and the Rise of Multiculturalism, Copp Clark Publishing, Toronto.

Simmons, A. y Keohane, K. (1992): "Canadian Immigration Policy: State strategies and the quest for legitimacy", en Canadian Review of Sociology and Anthropology, vol. 24, n. ${ }^{\circ}$, pp. 421452.

Statistics Canada (2008): Profile of Ethnic Origin and Visible Minorities, 2006 Census, Ottawa.

Troper, H. (2003): "To Farms or Cities: A Historical Tension between Canada and its Immigrants", en Reitz, J. (ed.), Host Societies and the Reception of Immigrant, Center for Comparative Immigration Studies, UCSD, San Diego.

Trudeau, P.; Stanfield, R. y Lewis, D. (1971): "House of Commons Debates", October 8, pp. 8545-8, en Palmer, H. (1975) (ed.), Immigration and The Rise of Multiculturalism, Copp Clark Publishing, Toronto.

Verduzco, G. y Lozano, I. (2003): Mexican Farm Workers' Participation in Canada's Seasonal Agricultural Labour Market and Development Consequences in the Rural Home Communities, North-South Institute, Ottawa.

Weil, P (2001): "Races at the Gate: a century of racial distinctions in American Immigration Policy (1865-1965)", en Georgetown Immigration Law Journal, vol. 15, n. ${ }^{\circ} 4$.

Whitaker, R. (1991): Canadian Immigration Policy since Confederation, Canadian Historical Association, Ottawa.

Wickberg, E. (1982): From China to Canada. A History of the Chinese Communities in Canada, McClelland y Steward, Toronto.

Zolberg, A. (2007): "The Exit Revolution", en Green, N. y Weil, F. (eds.), Citizenship and Those Who Leave, The Politics of Emigration and Expatriation, University of Illinois, Chicago, pp. 33-59 